\title{
Biological—waste as resource, with a focus on food waste
}

\author{
Ming-Hung Wong ${ }^{1,2} \cdot$ Yong-Sik $\mathrm{Ok}^{3} \cdot$ Ravi Naidu $^{4}$
}

Received: 27 October 2015 / Accepted: 6 January 2016/Published online: 22 January 2016

(C) Springer-Verlag Berlin Heidelberg 2016

\section{PREFACE}

The selected papers included in this special issue were presented in the meeting entitled "Biological Waste as Resource with a Focus on Food Waste" held during 1-3 December 2014 at The Hong Kong Institute of Education, Tai Po, Hong Kong. It was organized jointly by the Consortium on Health, Environment, Education and Research (CHEER), Centre for Education in Environmental Sustainability (CEES), The Hong Kong Institute of Education, and Croucher Institute for Environmental Sciences, Hong Kong Baptist University, and sponsored by the Environment Conservation Fund (ECF) of the Hong Kong Environmental Protection Department.

The conference focused on "recycling" and "recovery" of organic waste (biomass) which included agricultural waste (plant residues and animal manure), biosolid (sewage sludge), food waste, paper/yard/wood waste, municipal waste, and waste cooking oil, through microbial degradation, to produce

Responsible editor: Philippe Garrigues

Ming-Hung Wong

minghwong@ied.edu.hk

1 Department of Science and Environmental Studies, Consortium on Health, Environment, Education and Research (CHEER), The Hong Kong Institute of Education, Hong Kong, China

2 School of Environment, Jinan University, Guangzhou, China

3 Korea Biochar Research Center, Environmental Remediation and Restoration Laboratory, School of Natural Resources and Environmental Science, Kangwon National University, Chuncheon 200-701, Gangwon Province, South Korea

4 Cooperative Research Centre for Contamination Assessment and Remediation of the Environment, ATC Building, University of Newcastle, Callaghan, NSW 2308, Australia valuable products and energy sources. "Recycling" is the reprocessing of materials into new products, which will lessen the environmental impact and at the same time conserve a significant amount of energy and raw materials, whereas "recovery" refers to the recovery of embedded energy within waste materials through energy generation. A special session is devoted to "food waste," as it is a timely topic in densely populated urban centres such as Hong Kong.

There were 55 oral and 21 poster presentations during the meeting. All the authors were invited to submit their full papers, to be included as a special issue of Environmental Science and Pollution Research (ESPR). There were more than 40 submissions. Each paper submitted was handled by a member of the Editorial Board of ESPR and sent out for review. Finally, only 16 papers were included in this special issue, after vigorously reviewed.

The ultimate goal of this special issue is to demonstrate the feasibility of converting biological wastes into resource and at the same time ease their disposal pressure, and also minimize pollution problems, due to improper treatment and disposal.

\section{Part I: General background (papers 1 and 2)}

Paper 1 deals with the waste generation and collection in Korea, which is known for her efficiency in waste collection and recycling among Asian countries. Some important data is generated via the automated pipeline-based vacuum collection (AVAC) system used in densely populated areas of Korea, as an alternative to the conventional mobile collection systems.

Paper 2 describes the food waste problem faced by Hong Kong, with 3600 tonnes of food waste generated daily from the population of over seven million. This has imposed tremendous pressure on its disposal. The potential usage of biogas to produce electricity and city gas from food wastes via the 
Organic Waste Treatment Facilities (a Hong Kong Government establishment) is discussed.

\section{Part II: Techniques and applications (papers 3-10)}

In the study conducted in Thailand, food waste is converted to biogas for energy recovery via a prototype single-stage anaerobic digester (paper 3), as an in situ energy recovery system from food wastes under the Ministry of Energy of Thailand.

Paper 4 shows an excellent example in co-composting biological wastes such as manures and biosolids, to stabilize carbon $(\mathrm{C})$, using alkaline materials. The product generated also contributes to the long-term soil $\mathrm{C}$ sequestration and reduction of bioavailability of heavy metals.

A review on the feasibility of biochar application on a landfill final cover is provided in paper 5. As a soil amendment, biochar changes key ecological factors including plant development, soil microbial community and nutrient/ contaminant recycling, and slope engineering factors such as soil weight, internal friction angle and cohesion.

The practical usage of biochar as an alternative landfill final cover material is described in paper 6 . Results revealed that the use of compacted biochar-amended clay was able to enhance the soil-gas permeability.

Paper 7 serves as an excellent example of producing useful products from wastes: a new adsorbent of manganese-oxidecoated fly ash prepared by wet impregnation of fly ash with manganese chloride solution, as a potential adsorbent for the removal of fluoride from aqueous solution.

Paper 8 describes an experiment related to production of microalgae-based biodiesel, from lipid-extracted microalgal wastes via anaerobic digestion. Results demonstrated the inhibitory effect of residual $n$-hexane derived from lipid extraction could inhibit metabolic pathway of methanogens, during the conversion of wastes to methane.

In this study (paper 9), separation and concentration of fatty acids from the synthetic food processing wastewater containing low concentration of fatty acids were studied, using expanded graphite as a novel adsorbent at different temperatures. Results indicated that fatty acids can be effectively harvested and concentrated using the technique.

Paper 10 shows that mixture of food waste and sewage sludge could serve as an excellent substrate for dark fermentative biohydrogen production. The best hydrogen yield, hydrogen production rate, and hydrogen content were achieved at the hydraulic retention time (HRT) of $72 \mathrm{~h}$, associated with the superior growth of Clostridium sp. and Bacillus sp.

\section{Part II: Food wastes as fish feeds (papers 11-16)}

Paper 11 attempts to assess the relative contributions of various pathways to the mass loadings of DDTs in cultured fish using a fish enrichment model. It was observed that fish feeds and seawater contributed approximately the same proportions for the DDTs detected in the cultured fish, while the antifouling paint was the primary source of water DDTs in the mariculture zone.

There seems to be an urgent need to produce fish feeds which contained lower levels of contaminants. Included in these sections are several papers related to the use of food wastes as fish feeds.

Paper 12 reviews the feasibility and techniques available of turning food wastes into fish feeds. It emphasized the use of food wastes to feed soldier fly (Hermetia illucens) in order to generate a higher grade protein.

Paper 13 describes a laboratorial trial feeding food wastes (collected from hotels) to grass carp (Ctenopharyngodon idella). It was revealed that being an herbivore, grass carp can utilize plant proteins better than animal proteins, and it also preferred carbohydrate as a major energy source than lipid.

Upgrading food wastes into better quality fish feeds would be essential. Paper 14 shows that by adding enzymes (bromelain from pine apple and papain from papaya) into food wastebased pellets could enhance growth and immunity of grass carp.

Paper 15 shows that food wastes generally contained lower protein and nutritional levels, but they can meet the demand of low-trophic level fish species, such as grass carp and tilapia, under polyculture (rearing different species in the same pond). In general, the cultured fish were safe for consumption, based on the heavy metals and persistent organic pollutants detected in the fish flesh.

Paper 16 further demonstrated that food waste-based pellets were suitable for culturing grass carp, and Napier grass (Pennisetum purpureum) could serve as supplemental feed to reduce the cost (compared with using pellet feeds alone).

It is hoped that this special issue will provide an excellent opportunity for experts from different parts of the world, who are working on relevant topics for exchanging information.

Acknowledgements Financial support from Environment Conservation Fund (ECF) of the Environmental Protection Department is gratefully acknowledged. MH Wong would also like to express his sincere gratitude to the active participation contributed by the Environment Bureau, Environmental Protection Department and Department of Agriculture, Fisheries and Conservation; and The Hong Kong Institute for Education, for the award of Seed Fund for Professor and Chair Professor. 


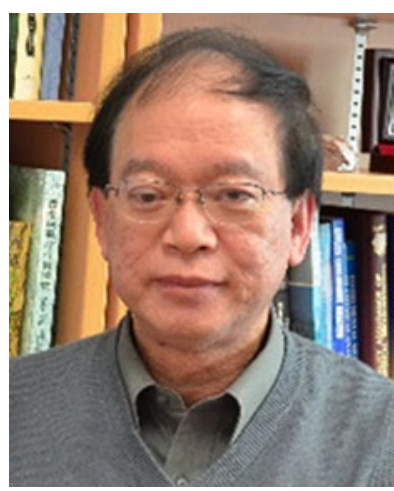

Professor Ming-Hung Wong is Research Chair Professor of Environmental Science, Hong Kong Institute of Education, Chang Jiang Chair Professor of Environmental Science (Jinan University) of Ministry of Education, China; and Emeritus Chair Professor of Biology, Hong Kong Baptist University. Having served as the Regional Coordinator of Central and North-East Asia of the project "Regionally Based Assessment of Persistent Toxic Substances" sponsored by United Nations Environment Program (UNEP) and Global Environment Facility (GEF), Prof. Wong has joined a panel of three to review a UNEP/GEF initiative "Emerging Chemicals Management Issues in Developing Countries and Countries with Economies in Transition" with the aim of understanding the sources and preventing adverse impacts of chemicals on human health and the environment in rapidly developing countries. Professor Wong has published over 580 SCI papers and 32 book chapters, edited 26 books/ special issues of scientific journals, and filed 5 patents. He has supervised 70 postgraduate students.

His reputation has been widely recognized internationally and capped by receiving two DSc Degrees awarded by University of Durham and University of Strathclyde in 1992 and 2004, respectively. He is currently the Editor-in-Chief of Environmental Geochemistry and Health (Elsevier), and Book Series Editor of Urbanization, Industrialization and the Environment (CRC/Taylor \& Francis).

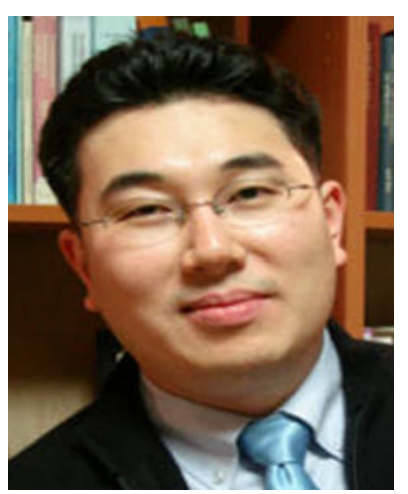

Dr. Yong-Sik Ok is a Full Professor at the Department of Biological Environment, Kangwon National University (KNU) and is currently serving as a Director of the Korea Biochar Research Center (KBRC) in Korea. During his academic career at KNU, Prof. Ok has supervised over 50 postgraduate students, postdoctoral fellows and visiting scientists from many countries including Korea, Taiwan, China, Saudi Arabia, Egypt, India, Pakistan and Sri Lanka. He has published more than 250 peer-reviewed journal articles until now and has been awarded the KNU Excellent Research Award in recognition of his outstanding achievements. Prof. Ok is currently serving as a Coordinating Editor for Environmental Geochemistry and Health, a Subject Editor for Journal of
Soils and Sediment, an Associate Editor for Canadian Journal of Soil Science and an Editorial Board Member for Chemical Speciation and Bioavailability. Additionally, he has served as a Guest Editor for a number of the leading journals.

As a Visiting Professor, Prof. Ok is also contributing to the Department of Renewable Resources, University of Alberta (Canada), the Faculty of Bioscience Engineering, Ghent University (Belgium) and the Department of Civil and Environmental Engineering, Hong Kong Polytechnic University (Hong Kong). Prof. Ok has organized many international conferences.

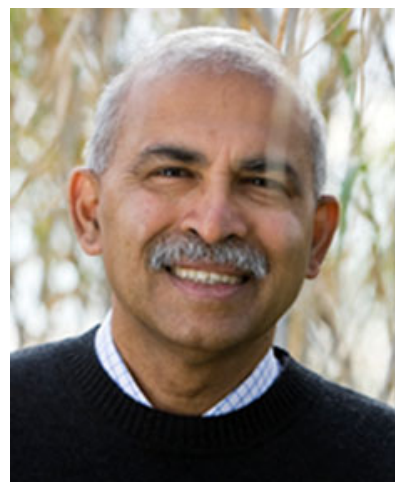

Professor Ravi Naidu is CEO and Managing Director, Cooperative Research Centre for Contamination Assessment and Remediation of the Environment (CRC CARE); and Global Innovation Chair and Director, Global Centre for Environmental Remediation, University of Newcastle, Australia.

Prof. Naidu's work focuses on the remediation of contaminated soil, water and air, and the potential impacts of contaminants upon environmental and human health at local, national and global levels. By demonstrating that contaminants only pose a risk if they can be taken up by humans, animals, plants and other biota with adverse effects, he has helped pioneer a more rational, effective and affordable approach to contamination science and actual clean-up, which has been adopted in Australia. Prof. Naidu is also the Global Innovation Chair and Director of the University of Newcastle's Global Centre for Environmental Remediation, and was the founding director of the University of South Australia's Centre for Environmental Risk Assessment and Remediation. In 2012 he was chosen as a winner of the Soil Science Society of America's International Soil Science Award, and in 2013 was elected a Fellow of the American Association for the Advancement of Science. $\mathrm{He}$ is Chair of the International Committee on Bioavailability and Risk Assessment and was Chair of the Standards Australia Technical Committee on Sampling and Analyses of Contaminated Soils (1999-2000), Chair of the International Union of Soil Sciences Commission for Soil Degradation Control, Remediation and Reclamation (2002-10), and President of the International Society on Trace Element Biogeochemistry (2005-07). He has authored or co-authored over 420 journal articles and 80 technical publications as well as seven patents, and co-edited 11 books and over 66 book chapters. He has also supervised over $30 \mathrm{PhD}$ completions. In 2013, Professor Naidu received an Honorary Doctorate of Science from Tamil Nadu Agricultural University, and the Richard Pratt - Banksia CEO Award. 